\title{
Encaging palladium(0) in layered double hydroxide: A sustainable catalyst for solvent-free and ligand-free Heck reaction in a ball mill
}

\author{
Wei Shi, Jingbo Yu, Zhijiang Jiang, Qiaoling Shao and Weike Su*
}

Open Access

\author{
Full Research Paper \\ Address: \\ National Engineering Research Center for Process Development of \\ Active Pharmaceutical Ingredients, Collaborative Innovation Center of \\ Yangtze River Delta Region Green Pharmaceuticals, Zhejiang \\ University of Technology, Hangzhou, 310014, Zhejiang, China \\ Email: \\ Weike Su* - pharmlab@zjut.edu.cn \\ * Corresponding author \\ Keywords: \\ ball milling; Heck reaction; layer double hydroxides; solvent-free; \\ supported Pd catalyst
}

\author{
Beilstein J. Org. Chem. 2017, 13, 1661-1668. \\ doi: $10.3762 /$ bjoc. 13.160 \\ Received: 22 April 2017 \\ Accepted: 18 July 2017 \\ Published: 14 August 2017 \\ This article is part of the Thematic Series "Mechanochemistry". \\ Guest Editor: J. G. Hernández \\ (C) 2017 Shi et al.; licensee Beilstein-Institut. \\ License and terms: see end of document.
}

\begin{abstract}
In this paper, the synthesis of a cheap, reusable and ligand-free Pd catalyst supported on MgAl layered double hydroxides ( $\mathrm{Pd} / \mathrm{MgAl}-\mathrm{LDHs}$ ) by co-precipitation and reduction methods is described. The catalyst was used in Heck reactions under highspeed ball milling (HSBM) conditions at room temperature. The effects of milling-ball size, milling-ball filling degree, reaction time, rotation speed and grinding auxiliary category, which would influence the yields of mechanochemical Heck reactions, were investigated in detail. The characterization results of XRD, ICP-MS and XPS suggest that Pd/MgAl-LDHs have excellent textural properties with zero-valence Pd on its layers. The reaction results indicate that the catalyst could be utilized in HSBM systems to afford a wide range of Heck coupling products in satisfactory yields. Furthermore, this catalyst could be easily recovered and reused for at least five times without significant loss of catalytic activity.
\end{abstract}

\section{Introduction}

High-speed ball milling (HSBM)-assisted transition metal-catalyzed cross-coupling reactions such as Heck, Suzuki, Sonogashira and Glaser reactions are still unusual methods for the formation of $\mathrm{C}-\mathrm{C}$ bonds [1-7], but the method arouse considerable attention because of an environmentally benign and solvent-free synthesis approach as well as high efficiency and good atom economy, which is desirable in the fields of chemistry, materials science, biology, pharmaceutical, dyestuff, agriculture and so forth [8-12].
The homogeneous palladium salts along with phosphine- or nitrogen-based ligands were employed as the traditional catalyst systems not only in solution-based $\mathrm{C}-\mathrm{C}$ cross coupling [1316] reactions but also in mechanically activated Heck [4,17-22], Suzuki [23-26], and Sonogashira [5,27,28] coupling reactions. The limitations of which are obviously unstable ligands and expensive Pd catalysts. Furthermore, the contamination of the coupled products with unacceptable Pd species led to a hard separation and recycling of homogeneous catalyst systems. In 
our previous study [4] we reported a ball-milling Heck reaction catalyzed by $\mathrm{Pd}(\mathrm{OAc})_{2}$. Although the catalyst showed the satisfactory reactivity, it was difficult to recover. Thus, Pd catalysts anchored on heterogeneous solid support materials such as MCM-41 [29], alumina [30], silica [31], carbon nanotubes [32], microporous polymers [33], SBA-15 [34], or some dendrimers [35] were preferred to develop a ligandless and recyclable catalyst system. However, to the best of our knowledge, only a few of supported Pd catalysts were used in mechanochemically assisted coupling reactions because of the low mechanical strength of the catalysts, the active component of which is easy to leach and deactivate under HSBM conditions. Mack and co-workers [36] reported a kind of polymer supported $\mathrm{Pd}\left(\mathrm{PPh}_{3}\right)_{4}$ catalyst with high activity in a Glaser reaction (Scheme 1). They found that the catalyst could only be recycled twice without the addition of the $\mathrm{PPh}_{3}$ ligand and the $\mathrm{Pd}$ component was significantly leached from polymer support after each run. Cravotto et al. [37] used an ultrasound-assisted method to prepare Pd catalysts immobilized on modified chitosan (Scheme 1). Although these catalysts were found to be effective in the Suzuki reaction after three cycles, the modification conditions of chitosan were rigorous.

As catalyst-supported material, layered double hydroxides (LDHs) have received much attention in the organic catalysis for its excellent properties such as low costs, high specific surface area, double-layered structure, anion exchange capacity, high mechanical stability and chemical stability [38-43]. Our previous studies have proved that LDH catalysts could be successfully applied in the degradation of organic pollutants $[44,45]$. Bai and co-worker [46] synthesized Pd/SDS-LDHs by using an ultrasonic method, which exhibited excellent activity in Suzuki reactions. Jiang et al. [47] demonstrated that LDHsupported on alkaline materials performed higher catalytic activity in coupling reactions than that on acidic-supported materials. In the present work, co-precipitation was used for fabricating MgAl-LDHs with nitrate anions, followed by introducing disodium tetrachloropalladate $\left(\mathrm{Na}_{2} \mathrm{PdCl}_{4}\right)$ into the LDH interlayer by the ion exchange method. The prepared hybrid LDHs were then reduced by hydrazine hydrate $\left(\mathrm{N}_{2} \mathrm{H}_{4} \cdot \mathrm{H}_{2} \mathrm{O}\right)$ to obtain the Pd catalyst supported on MgAl-LDHs ( $\mathrm{Pd} / \mathrm{MgAl}-\mathrm{LDHs}$ ). The as-prepared $\mathrm{Pd} / \mathrm{MgAl}-\mathrm{LDH}$ catalyst was further applied in representative cross-coupling Heck reactions under HSBM conditions (Scheme 1) by using a planetary ball mill (Pulverisette 7, Fritsch, Germany). The influence of milling-ball filling degree $\left(\Phi_{\mathrm{MB}}\right)$, reaction time $(t)$, milling-ball size $\left(d_{\mathrm{MB}}\right)$ and rotation speed $(n)$, along with catalyst loading, alkaline type and grinding auxiliary category were further investigated in detail.

\section{Results and Discussion Characteristics of prepared materials}

We initially prepared the Pd/MgAl-LDHs catalyst as described in the Experimental section (see Supporting Information File 1). Figure 1 shows the powder XRD patterns of MgAl-LDHs, MgAl-LDHs-PdCl ${ }_{4}{ }^{2-}$ and Pd/MgAl-LDHs at $2 \theta=5-80^{\circ}$. All samples have diffraction peaks located around $10^{\circ}, 20^{\circ}, 33^{\circ}$, $38^{\circ}, 60^{\circ}$, indexing to (003), (006), (009), (015), (110) reflections, which indicates the highly neat degree and well-crystallinity structure of LDH materials without phase impurities apparent. Moreover, the MgAl-LDHs presents an interlayer distance of $0.82 \mathrm{~nm}$ from the basal spacing of $d_{003}$, which matches the results well for the intercalation of nitrate $\left(\mathrm{NO}_{3}{ }^{-}\right)$into $\mathrm{MgAl}-\mathrm{LDHs}$ in literature [48]. In the MgAl-LDHs- $\mathrm{PdCl}_{4}{ }^{2-}$

previous works:
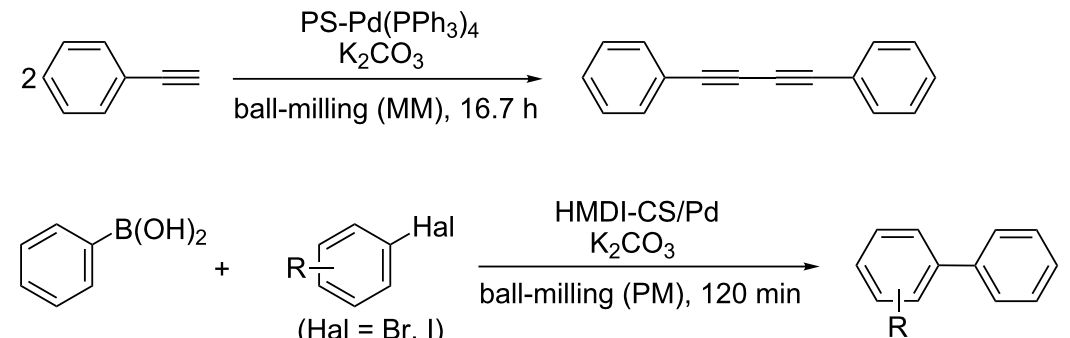

$(\mathrm{Hal}=\mathrm{Br}, \mathrm{I})$

this work:
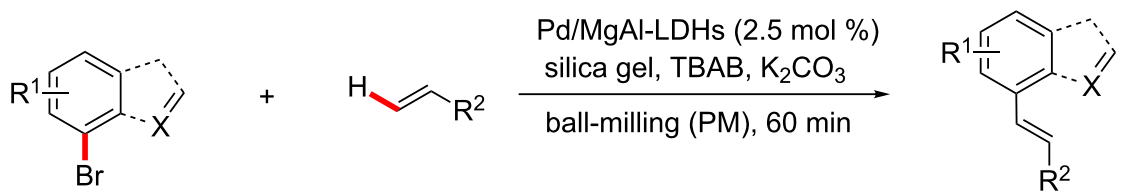
sample, the (003) plane shifted to the lower position of $8.8^{\circ}$, resulting to an expansion of interlayer spacing of $1.01 \mathrm{~nm}$ from $0.82 \mathrm{~nm}$. These phenomena suggest that $\mathrm{PdCl}_{4}{ }^{2-}$ successfully intercalated into the MgAl-LDHs interlayers. As compared with MgAl-LDHs and MgAl-LDHs- $\mathrm{PdCl}_{4}{ }^{2-}$, the catalyst of $\mathrm{Pd} /$ MgAl-LDHs exhibited a lower intensity pattern except for the diffraction peaks at $38^{\circ}$ and $44^{\circ}$, which was due to the random dispersion of the Pd component on the Pd/MgAl-LDHs surface. The Pd loading of catalyst was $8.5 \mathrm{wt} \%$, and the molar ratio of $\mathrm{Mg}$ and $\mathrm{Al}$ in LDH layers were 2.97, which is in accordance with the ratio of 3.00 employed in the synthesis step (see Table S1 in the Supporting Information File 1). Furthermore, the binding energy of $\mathrm{Pd} 3 \mathrm{~d}_{5 / 2}$ and $\mathrm{Pd} 3 \mathrm{~d}_{3 / 2}$ in $\mathrm{LDH}$ layers approximately centered at $334.7 \mathrm{eV}$ and $340.2 \mathrm{eV}$, respectively, assigning to the existence zero oxidation state of $\mathrm{Pd}$ bulk (around $335.0 \mathrm{eV}$ and $341.0 \mathrm{eV}[49,50]$ ), verified that $\mathrm{PdCl}_{4}{ }^{2-}$ had been reduced to zero-valence Pd from interlayers and loaded on MgAl-LDH surface successfully (see Figure S1 in Supporting Information File 1).

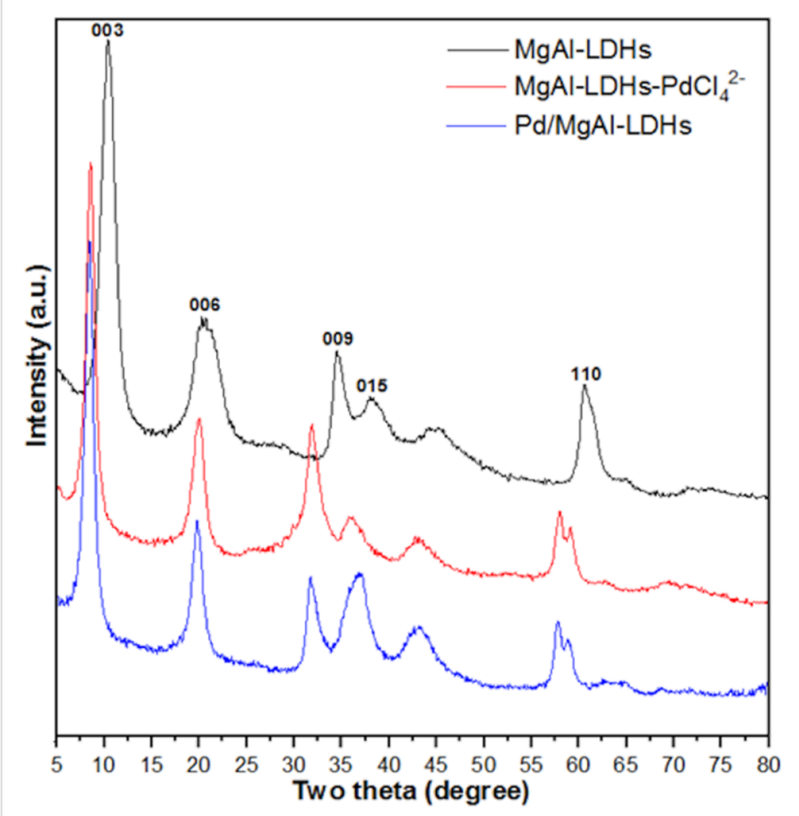

Figure 1: The XRD patterns for the samples of MgAl-LDHs, MgAlLDHs-PdCl ${ }_{4}^{2-}$ and Pd/MgAl-LDHs.

\section{The Heck coupling reaction under HSBM conditions}

$m$-Bromoacetophenone (1a) and styrene (2a) were chosen as the model reactants (Scheme 2), catalyzed by Pd/MgAl-LDHs under ball-milling conditions with silica gel $(5 \mathrm{~g})$ and stainlesssteel balls $\left(\Phi_{\mathrm{MB}}=0.2, d_{\mathrm{MB}}=14 \mathrm{~mm}\right)$ at $800 \mathrm{rpm}$.

Based on our previous researches [4,51], it is found that the bases used have a significant influence on the yields of the reaction. Thus, several bases such as $\mathrm{NaOH}, \mathrm{KOH}, \mathrm{Cs}_{2} \mathrm{CO}_{3}$, $\mathrm{K}_{2} \mathrm{CO}_{3}, t$-BuOK, $\mathrm{Et}_{3} \mathrm{~N}$ and $\mathrm{DBU}$ were investigated and the results are shown in Table 1. It is notable that both inorganic and organic bases could facilitate the reaction successfully. $\mathrm{K}_{2} \mathrm{CO}_{3}$ exhibited the best yield of $72 \%$ (Table 1, entries 1-7) as compared with other bases for the reaction. In further tests, different loadings of $\mathrm{Pd} / \mathrm{MgAl}-\mathrm{LDH}$ s were employed in the model reaction (Table 1, entries 8-10) in order to optimize the usage of catalyst. The results show that the reaction yield kept unchanged when the Pd/MgAl-LDHs loading was reduced to 2.5 mol \% (Table 1, entry 9).

After getting access to the optimal reactant system, we shifted our focus on the mechanochemistry parameters of mill-ball size and its filling degree. The milling-ball filling degree $\left(\Phi_{\mathrm{MB}}\right)$ represents the volume of the milling balls relative to the beaker volume, which is calculated as the ratio of the overall milling ball volume $\left(V_{\mathrm{MB}}\right)$ to the total beaker volume $\left(V_{\mathrm{BV}}\right)$ :

$$
\Phi_{\mathrm{MB}}=\frac{\sum V_{\mathrm{MB}}}{V_{\mathrm{BV}}}
$$

This parameter is proved to be the essential factor not only on the occurrence of collision and friction, but also on the energy distribution and product yield [52]. In Figure 2, we chose four types of milling-balls with diameters of $5 \mathrm{~mm}, 8 \mathrm{~mm}, 10 \mathrm{~mm}$ and $14 \mathrm{~mm}$ in the model reaction under four kinds of filling degrees $\left(\Phi_{\mathrm{MB}}=0.15,0.2,0.25,0.3\right)$. It could be found that no matter which kind of the milling-ball diameter is, the tendency of the product yield is similar under different filling degrees. A maximum yield (84\%) was obtained by using $5 \mathrm{~mm}$ milling balls at 0.25 filling degree. In addition, the $14 \mathrm{~mm}$ milling balls

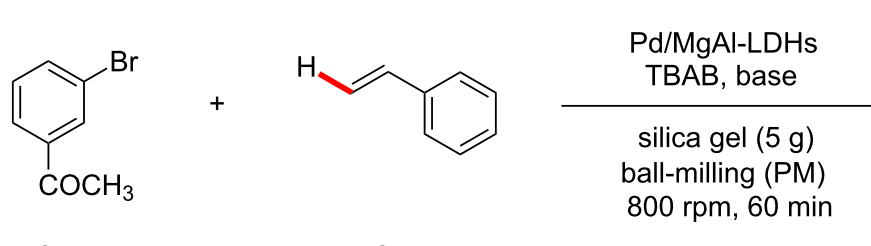

$1 a$
$2 a$<smiles>CC(=O)c1cccc(C=Cc2ccccc2)c1</smiles>

3aa 
Table 1: Optimization of Heck reaction conditions. ${ }^{\text {a }}$

\begin{tabular}{llll} 
Entry & Base & $\mathrm{Pd}(\mathrm{mol} \%)$ & Yield $(\%)^{\mathrm{b}}$ \\
\hline 1 & $\mathrm{NaOH}$ & 10 & 56 \\
2 & $\mathrm{KOH}$ & 10 & 64 \\
3 & $t$-BuOK & 10 & 59 \\
4 & $\mathrm{Et}_{3} \mathrm{~N}$ & 10 & 54 \\
5 & $\mathrm{Cs}_{2} \mathrm{CO}_{3}$ & 10 & 60 \\
6 & $\mathrm{~K}_{2} \mathrm{CO}_{3}$ & 10 & 72 \\
7 & $\mathrm{DBU}_{8}$ & 10 & 43 \\
8 & $\mathrm{~K}_{2} \mathrm{CO}_{3}$ & 5 & 71 \\
9 & $\mathrm{~K}_{2} \mathrm{CO}_{3}$ & 2.5 & 71 \\
10 & $\mathrm{~K}_{2} \mathrm{CO}_{3}$ & 1.25 & 54 \\
\hline
\end{tabular}

${ }^{a}$ Reaction conditions unless otherwise noted: $\mathbf{1 a}(1.5 \mathrm{mmol}), \mathbf{2 a}$ (2.1 mmol), Pd/MgAl-LDHs, TBAB (1.5 mmol), base (3.6 mmol), and $5 \mathrm{~g}$ silica gel were placed in a $80 \mathrm{~mL}$ stainless-steel vessel $\left(\Phi_{\mathrm{MB}}=0.2\right.$ $d_{\mathrm{MB}}=14 \mathrm{~mm}$ ). HSBM conditions: $60 \mathrm{~min}$ at $800 \mathrm{rpm}$. b/solated yield.

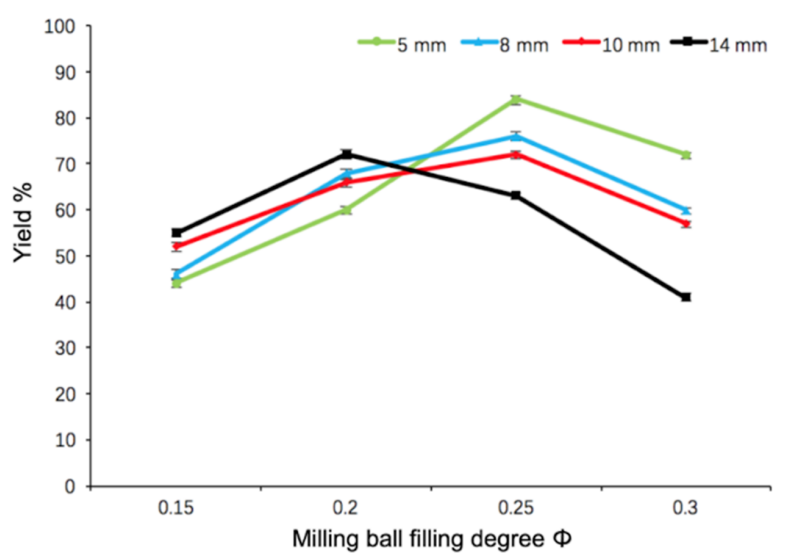

Figure 2: Examination of the milling-ball filling degree $\left(\Phi_{\mathrm{MB}}\right)$ and milling-ball sizes on the yield of 3aa. Reaction conditions: 1a (1.5 mmol), 2a (2.1 mmol), Pd/MgAl-LDHs (2.5 mol \%), TBAB $(1.5 \mathrm{mmol}), \mathrm{K}_{2} \mathrm{CO}_{3}(3.6 \mathrm{mmol}), 5 \mathrm{~g}$ silica gel were placed in a $80 \mathrm{~mL}$ stainless-steel vessel. HSBM conditions: $60 \mathrm{~min}$ at $800 \mathrm{rpm}$.

exhibited the higher yields than $5 \mathrm{~mm}, 8 \mathrm{~mm}$ and $10 \mathrm{~mm}$ milling balls under the low filling degrees $\left(\Phi_{\mathrm{MB}}=0.15,0.2\right)$. And then, with the filling degree increased to the value of 0.25 , the movement space for $14 \mathrm{~mm}$ milling balls was hindered in the ball-milling jar, resulting in the apparent decrease in the yield of 3aa. On the contrary, $5 \mathrm{~mm}, 8 \mathrm{~mm}$ and $10 \mathrm{~mm}$ milling balls had sufficient collision to produce enough energy under the filling degree of 0.25 , leading to the high yields. Furthermore, the sharp decrease in the yield could be also observed in $5 \mathrm{~mm}, 8 \mathrm{~mm}$ and $10 \mathrm{~mm}$ milling-ball systems with a filling degree over 0.25 , which might be due to the overfull ballmilling jar and the overabundant energy input. These results mentioned above are consistent with the previous studies reported by us [53] and the others [52,54].
Because the ball-milling time and the rotation speed have a strong influence on the energy input, which directly regulates the product structure and yield during the mechanochemical process, the combined effect of ball-milling time and rotation speed was investigated systematically. The results are summarized in Figure 3. It can be seen that with increasing rotation speed, the yield of 3aa increased first, but decreased at the highest speed of $1000 \mathrm{rpm}$. This is mainly due to the overabundant energy input resulting in side products. Furthermore, prolonging the reaction time over $60 \mathrm{~min}$ did not help improving the product yield, the reactants had all been consumed after $60 \mathrm{~min}$. Therefore, $800 \mathrm{rpm}$ together with $60 \mathrm{~min}$ is regarded as the optimum condition for the maximum yield.

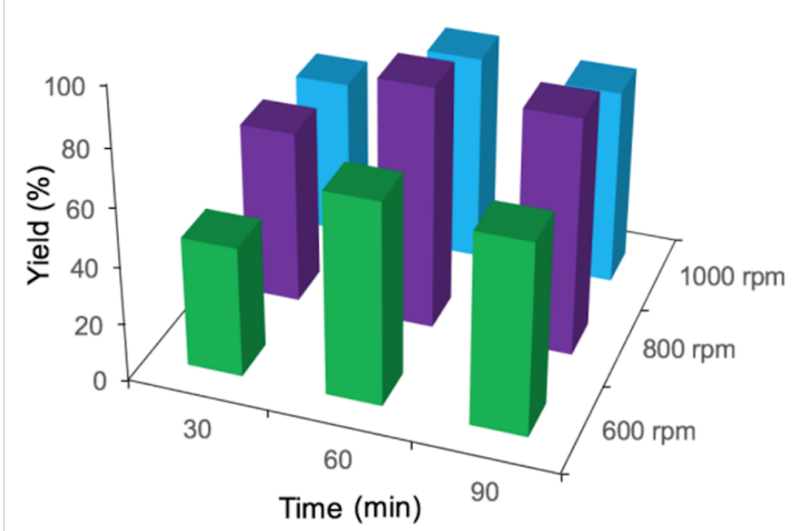

Figure 3: Examination of ball-milling time and rotation speed on the yield of 3aa. Reaction conditions: $1 \mathrm{a}(1.5 \mathrm{mmol}), 2 \mathrm{a}(2.1 \mathrm{mmol}), \mathrm{Pd} /$ MgAl-LDHs (2.5 mol \%), TBAB (1.5 mmol), $\mathrm{K}_{2} \mathrm{CO}_{3}(3.6 \mathrm{mmol})$, and $5 \mathrm{~g}$ silica gel were placed in a $80 \mathrm{~mL}$ stainless-steel vessel $\left(\Phi_{M B}=0.25\right.$, $d_{\mathrm{MB}}=5 \mathrm{~mm}$ ). HSBM conditions: $60 \mathrm{~min}$ at $800 \mathrm{rpm}$.

In the ball-milling process, the grinding auxiliary is found to be an efficient transfer medium between energy and reactant $[1,2,55,56]$. Additional investigations on the effects of the grinding auxiliaries were carried out. The results shown in Table 2 indicate that $5 \mathrm{~g}$ silica gel is considered as the most effective choice for the reaction (Table 2, entry 1), but MgAlLDHs gave also a good result (Table 2, entry 5). With $\mathrm{NaCl}$, $\alpha-\mathrm{Al}_{2} \mathrm{O}_{3}$ and $\gamma-\mathrm{Al}_{2} \mathrm{O}_{3}$, the yields were unsatisfactory (Table 2, entries 2-4). Increasing or decreasing the amount of silica gel would led to a reduction of the yield of 3aa (Table 2, entries 6 and 7), which might be due to the uneven distribution of the reactants.

After having the optimum reaction conditions in hand, the $\mathrm{Pd}$ / MgAl-LDH catalyst was evaluated to expand the generality and substrate scope in Heck reactions, the results are presented in Figure 4 and Scheme 3. As we expected, both with electronwithdrawing and electron-donating groups substituted bromobenzenes $(\mathbf{1} \mathbf{a}-\mathbf{l})$ and styrenes $(\mathbf{2 a}-\mathbf{e})$ react with each other 
Table 2: Examination of grinding auxiliaries on yield of 3aa. ${ }^{a}$

\begin{tabular}{|c|c|c|c|}
\hline Entry & Grinding auxiliary & Weight (g) & Yield (\%) \\
\hline 1 & silica-gel & 5 & $84{\text { (n.r. })^{b}}^{b}$ \\
\hline 2 & $\mathrm{NaCl}$ & 5 & 54 \\
\hline 3 & $\alpha-\mathrm{Al}_{2} \mathrm{O}_{3}$ (base) & 5 & 68 \\
\hline 4 & $\mathrm{~V}-\mathrm{Al}_{2} \mathrm{O}_{3}$ (neutral) & 5 & 61 \\
\hline 5 & MgAl-LDHs & 5 & $72(\text { n.r. })^{c}$ \\
\hline 6 & silica-gel & 3 & 74 \\
\hline 7 & silica-gel & 7 & 70 \\
\hline
\end{tabular}

${ }^{a}$ Reaction conditions unless otherwise noted: $1 \mathrm{a}(1.5 \mathrm{mmol}), 2 \mathrm{a}(2.1 \mathrm{mmol}), \mathrm{Pd} / \mathrm{MgAl}-\mathrm{LDHs}(2.5 \mathrm{~mol} \%), \mathrm{TBAB}_{(1.5 \mathrm{mmol}), \mathrm{K}_{2} \mathrm{CO}}(3.6 \mathrm{mmol})$, grinding auxiliary were placed in a $80 \mathrm{~mL}$ stainless-steel vessel $\left(\Phi_{\mathrm{MB}}=0.25, d_{\mathrm{MB}}=5 \mathrm{~mm}\right)$. HSBM conditions: $60 \mathrm{~min}$ at $800 \mathrm{rpm}$. bSilica gel used as grinding auxiliary without $\mathrm{Pd} / \mathrm{MgAl}-\mathrm{LDHs}$ catalyst. ${ }^{\mathrm{C}} \mathrm{MgAl}-\mathrm{LDH}$ s used as grinding auxiliary without Pd/MgAl-LDHs catalyst.

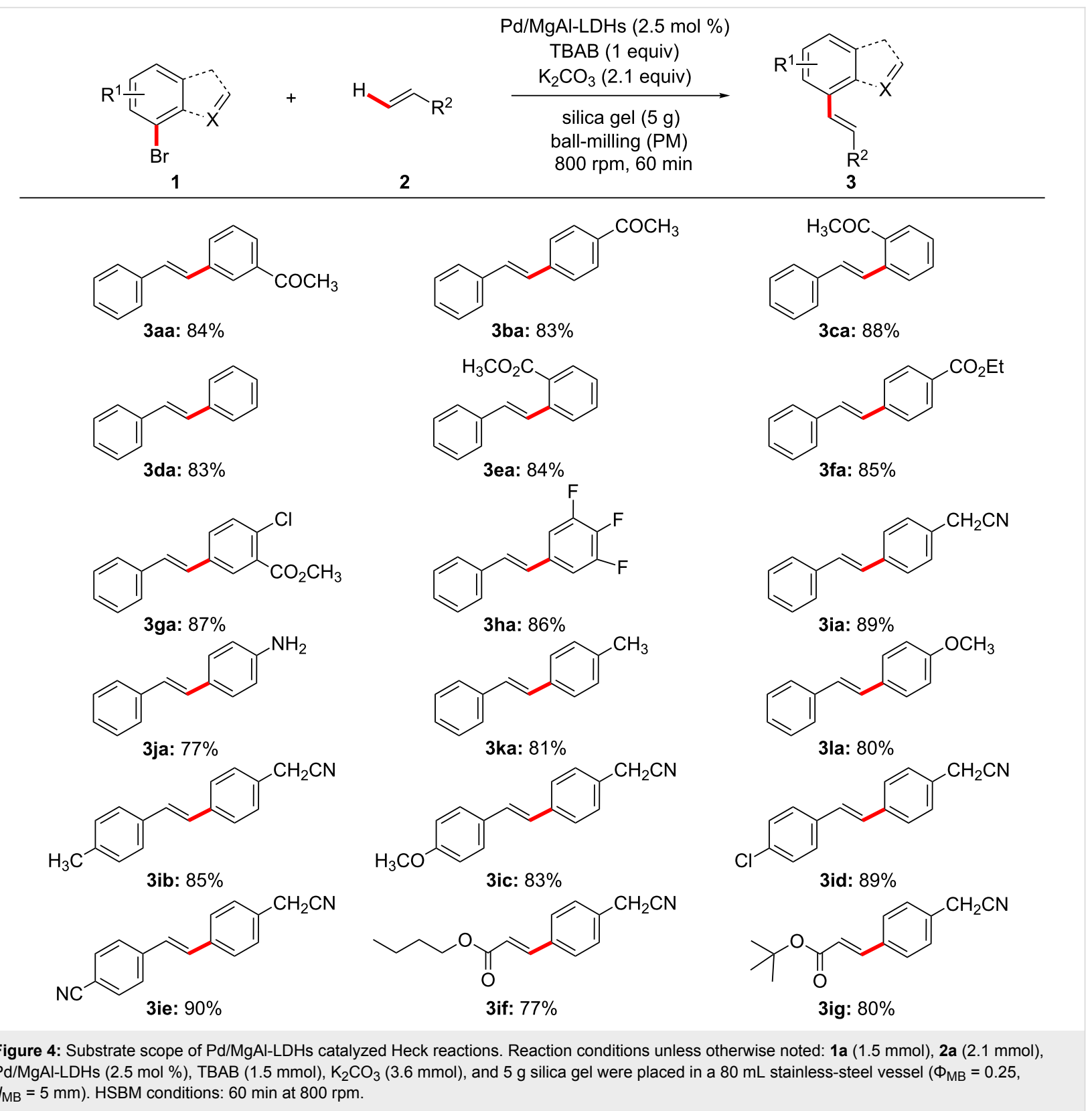




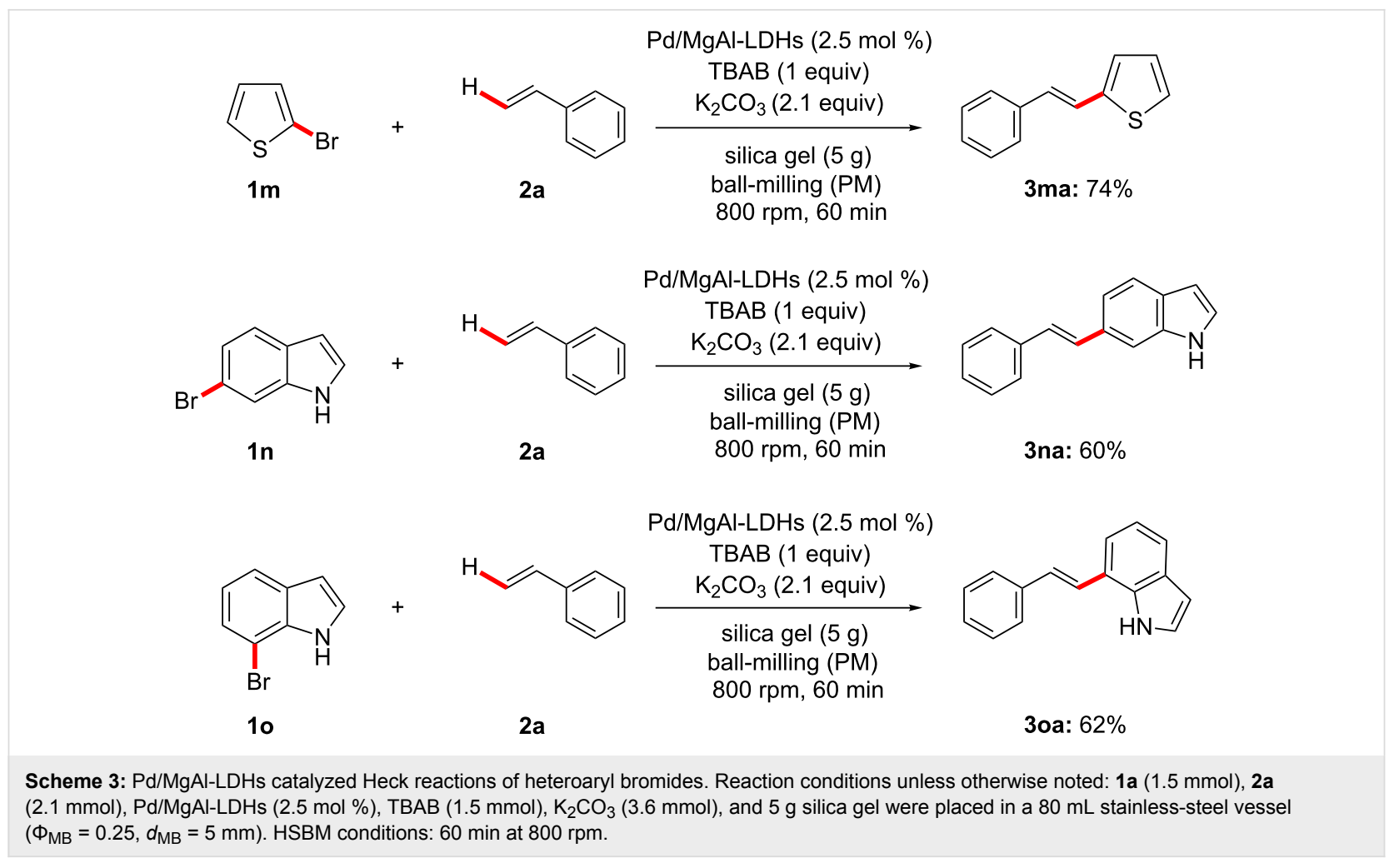

successfully to afford the coupling products in satisfactory yields. The electron-deficient bromobenzenes $(\mathbf{1 a}-\mathbf{c}, \mathbf{1}-\mathbf{e}-\mathbf{i})$ or styrenes (2d, 2e) show slightly higher yields than the electronrich substrates. The ketone group at ortho-, meta- and para-positions $(\mathbf{1 a}-\mathbf{c})$ were chosen to examine the steric hindrance for this reaction. To our surprise, the position of the ketone group had a little effect on the yields and the larger sterically hindered substrate 1c led to a higher yield as compared with $\mathbf{1 a}$ and $\mathbf{1 b}$, which is contrary to Li's study [57] in solution-based Heck reactions. This might be because of the lone pairs of the oxygen atom in the keto group at the ortho-position could coordinate with $\mathrm{Pd} / \mathrm{MgAl}-\mathrm{LDHs}$ under HSBM conditions and promote the reaction efficiently. Furthermore, the couplings of heteroaryl bromides (1 $\mathbf{m}-\mathbf{0})$ and styrene (2a) as well as substituted bromobenzene (1i) and butyl acrylate (2f, $\mathbf{2 g}$ ) were investigated to extend the scope and generality of the reaction. The results clearly demonstrate that all the substrates are well tolerated to give the corresponding coupling products smoothly with yields of $60-80 \%$.

Finally, the coupling reactions of aryl bromide $\mathbf{1 i}$ and styrene (2a) as well as heterocyclic bromide $\mathbf{1 m}$ and styrene (2a) were chosen as the model reactions under the optimized conditions to investigate the reusability of the $\mathrm{Pd} / \mathrm{MgAl}-\mathrm{LDH}$ catalyst. The catalyst together with the grinding auxiliary are recovered by a simple rinse after each run, which is more convenient compared to other methods [36,37]. As can be seen in Figure 5, regardless of the substrate type, the catalyst system could be reused at least five times efficiently without significant loss in catalytic activity, resulting in almost no change in the yields. Hence, the reusability of $\mathrm{Pd} / \mathrm{MgAl}-\mathrm{LDHs}$ is one of the major advantages for Heck reactions under HSBM conditions.

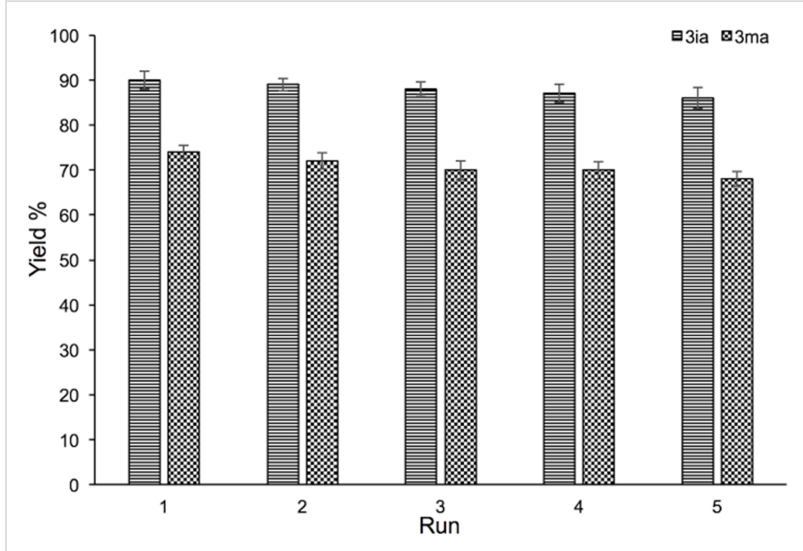

Figure 5: Recycling studies of the Pd/MgAl-LDH catalyst for Heck reactions. Reaction conditions: $1 \mathrm{i}$ or $1 \mathrm{~m}(1.5 \mathrm{mmol}), 2 \mathrm{a}(2.1 \mathrm{mmol})$, $\mathrm{Pd} / \mathrm{MgAl}-\mathrm{LDHs}$ (2.5 mol \%), TBAB (1.5 mmol), $\mathrm{K}_{2} \mathrm{CO}_{3}$ (3.6 mmol), and silica gel $5 \mathrm{~g}$ were placed in a $80 \mathrm{~mL}$ stainless-steel vessel $\left(\Phi_{\mathrm{MB}}=0.25, d_{\mathrm{MB}}=5 \mathrm{~mm}\right)$. HSBM conditions: $60 \mathrm{~min}$ at $800 \mathrm{rpm}$.

\section{Conclusion}

In summary, a supported and recyclable Pd catalyst (Pd/MgAl-LDHs) was designed and synthesized by co-precipi- 
tation and reduction methods. The catlyst was further applied to Heck reactions under HSBM conditions. The results indicate that the $\mathrm{Pd}$ is successfully dispersed on the surface of $\mathrm{Pd} / \mathrm{MgAl}-$ LDHs, and a small quantity of Pd/MgAl-LDHs $(2.5 \mathrm{~mol} \%$ of Pd) shows the remarkable activity in Heck reactions with a wide range of aryl bromides and olefins under mild conditions. In these cases, toxic solvents, expensive ligands and inert atmosphere were efficiently avoided. Furthermore, the Pd/MgAlLDH catalyst can be recycled for at least five times without significant loss in coupling product yields.

\section{Supporting Information}

\section{Supporting Information File 1}

Details of experimental procedures and characterization data of prepared compounds, ${ }^{1} \mathrm{H},{ }^{13} \mathrm{C}$ NMR, and MS spectra of all coupling compounds. [http://www.beilstein-journals.org/bjoc/content/ supplementary/1860-5397-13-160-S1.pdf]

\section{Acknowledgement}

This work was supported by the National Natural Science Foundation of China (No. 21406201) and the Special Program for Key Basic Research of the Ministry of Science and Technology, China (No. 2014CB460608).

\section{References}

1. Stolle, A.; Szuppa, T.; Leonhardt, S. E. S.; Ondruschka, B. Chem. Soc. Rev. 2011, 40, 2317-2329. doi:10.1039/c0cs00195c

2. Hermann, G. N.; Becker, P.; Bolm, C. Angew. Chem., Int. Ed. 2015, 54, 7414-7417. doi:10.1002/anie.201502536

3. Jiang, Z.-J.; Li, Z.-H.; Yu, J.-B.; Su, W.-K. J. Org. Chem. 2016, 81, 10049-10055. doi:10.1021/acs.joc.6b01938

4. Zhu, X.; Liu, J.; Chen, T.; Su, W. Appl. Organomet. Chem. 2012, 26, 145-147. doi:10.1002/aoc.2827

5. Thorwirth, R.; Stolle, A.; Ondruschka, B. Green Chem. 2010, 12, 985-991. doi:10.1039/c000674b

6. Bernhardt, F.; Trotzki, R.; Szuppa, T.; Stolle, A.; Ondruschka, B. Beilstein J. Org. Chem. 2010, 6, No. 7. doi:10.3762/bjoc.6.7

7. Hernández, J. G.; Bolm, C. J. Org. Chem. 2017, 82, 4007-4019. doi:10.1021/acs.joc.6b02887

8. Wang, G.-W. Chem. Soc. Rev. 2013, 42, 7668-7700. doi:10.1039/c3cs35526h

9. Hernández, J. G.; Friščić, T. Tetrahedron Lett. 2015, 56, 4253-4265. doi:10.1016/j.tetlet.2015.03.135

10. Lou, S.-J.; Mao, Y.-J.; Xu, D.-Q.; He, J.-Q.; Chen, Q.; Xu, Z.-Y. ACS Catal. 2016, 6, 3890-3894. doi:10.1021/acscatal.6b00861

11. Li, L.; Wang, J.-J.; Wang, G.-W. J. Org. Chem. 2016, 81, 5433-5439. doi:10.1021/acs.joc.6b00786

12. Do, J.-L.; Friščić, T. ACS Cent. Sci. 2017, 3, 13-19. doi:10.1021/acscentsci.6b00277

13. Phan, N. T. S.; Van Der Sluys, M.; Jones, C. W. Adv. Synth. Catal. 2006, 348, 609-679. doi:10.1002/adsc.200505473
14. Amatore, C.; Jutand, A. Acc. Chem. Res. 2000, 33, 314-321. doi:10.1021/ar980063a

15. Littke, A. F.; Dai, C.; Fu, G. C. J. Am. Chem. Soc. 2000, 122, 4020-4028. doi:10.1021/ja0002058

16. Chinchilla, R.; Nájera, C. Chem. Soc. Rev. 2011, 40, 5084-5121. doi:10.1039/c1cs15071e

17. Tullberg, E.; Peters, D.; Frejd, T. J. Organomet. Chem. 2004, 689, 3778-3781. doi:10.1016/j.jorganchem.2004.06.045

18. Tullberg, E.; Schacher, F.; Peters, D.; Frejd, T. Synthesis 2006, 1183-1189. doi:10.1055/s-2006-926371

19. Alonso, F.; Beletskaya, I. P.; Yus, M. Tetrahedron 2005, 61, 11771-11835. doi:10.1016/j.tet.2005.08.054

20. Declerck, V.; Colacino, E.; Bantreil, X.; Martinez, J.; Lamaty, F. Chem. Commun. 2012, 48, 11778-11780. doi:10.1039/c2cc36286d

21. Chen, X.; Engle, K. M.; Wang, D.-H.; Yu, J.-Q. Angew. Chem., Int. Ed. 2009, 48, 5094-5115. doi:10.1002/anie.200806273

22. Kantchev, E. A. B.; O'Brien, C. J.; Organ, M. G. Angew. Chem., Int. Ed. 2007, 46, 2768-2813. doi:10.1002/anie.200601663

23. Schneider, F.; Szuppa, T.; Stolle, A.; Ondruschka, B.; Hopf, H. Green Chem. 2009, 11, 1894-1899. doi:10.1039/b915744c

24. Schneider, F.; Ondruschka, B. ChemSusChem 2008, 1, 622-625. doi:10.1002/cssc.200800086

25. Schneider, F.; Stolle, A.; Ondruschka, B.; Hopf, H. Org. Process Res. Dev. 2009, 13, 44-48. doi:10.1021/op800148y

26. Lai, Y.; Zong, Z.; Tang, Y.; Mo, W.; Sun, N.; Hu, B.; Shen, Z.; Jin, L.; Sun, W.-h.; Hu, X. Beilstein J. Org. Chem. 2017, 13, 213-221. doi:10.3762/bjoc. 13.24

27. Fulmer, D. A.; Shearouse, W. C.; Medonza, S. T.; Mack, J. Green Chem. 2009, 11, 1821-1825. doi:10.1039/b915669k

28. Stolle, A.; Ondruschka, B. Pure Appl. Chem. 2011, 83, 1343-1349. doi:10.1351/PAC-CON-10-09-26

29. Noori, N.; Nikoorazm, M.; Ghorbani-Choghamarani, A. J. Porous Mater. 2016, 23, 1467-1481. doi:10.1007/s10934-016-0207-y

30. Gniewek, A. J. Organomet. Chem. 2016, 823, 90-96. doi:10.1016/j.jorganchem.2016.09.018

31. Ghasemi, S.; Farjadian, F.; Tamami, B. Appl. Organomet. Chem. 2016, 30, 818-822. doi:10.1002/aoc.3508

32. Hajighorbani, M.; Hekmati, M. RSC Adv. 2016, 6, 88916-88924. doi:10.1039/C6RA19934H

33. Wang, C.-A.; Li, Y.-W.; Hou, X.-M.; Han, Y.-F.; Nie, K.; Zhang, J.-P. ChemistrySelect 2016, 1, 1371-1376. doi:10.1002/slct.201600174

34. Satapathy, A.; Gadge, S. T.; Kusumawati, E. N.; Harada, K.; Sasaki, T.; Nishio-Hamane, D.; Bhanage, B. M. Catal. Lett. 2015, 145, 824-833. doi:10.1007/s10562-015-1489-4

35. Lu, F.; Astruc, D. Eur. J. Inorg. Chem. 2015, 5595-5600. doi:10.1002/ejic.201501103

36. Chen, L.; Lemma, B. E.; Rich, J. S.; Mack, J. Green Chem. 2014, 16, 1101-1103. doi:10.1039/C3GC41847B

37. Cravotto, G.; Garella, D.; Tagliapietra, S.; Stolle, A.; Schüßler, S.; Leonhardt, S. E. S.; Ondruschka, B. New J. Chem. 2012, 36, 1304-1307. doi:10.1039/c2nj40064b

38. Alexandre, M.; Dubois, P. Mater. Sci. Eng., R 2000, 28, 1-63. doi:10.1016/S0927-796X(00)00012-7

39. Parlett, C. M. A.; Wilson, K.; Lee, A. F. Chem. Soc. Rev. 2013, 42, 3876-3893. doi:10.1039/C2CS35378D

40. Fan, G.; Li, F.; Evans, D. G.; Duan, X. Chem. Soc. Rev. 2014, 43, 7040-7066. doi:10.1039/C4CS00160E

41. Li, C.; Wei, M.; Evans, D. G.; Duan, X. Catal. Today 2015, 247, 163-169. doi:10.1016/j.cattod.2014.05.032 
42. Gómez-Avilés, A.; Aranda, P.; Ruiz-Hitzky, E. Appl. Clay Sci. 2016, 130, 83-92. doi:10.1016/j.clay.2015.12.011

43. Takehira, K. Appl. Clay Sci. 2017, 136, 112-141. doi:10.1016/j.clay.2016.11.012

44.Xia, S.-J.; Liu, F.-X.; Ni, Z.-M.; Shi, W.; Xue, J.-L.; Qian, P.-P. Appl. Catal., B 2014, 144, 570-579. doi:10.1016/j.apcatb.2013.07.060

45. Xia, S.-j.; Zhou, X.-b.; Shi, W.; Pan, G.-x.; Ni, Z.-m. J. Mol. Catal. A: Chem. 2014, 392, 270-277. doi:10.1016/j.molcata.2014.05.028

46. Li, J. Z.; Bai, X. F. J. Mater. Sci. 2016, 51, 9108-9122. doi:10.1007/s10853-016-0164-5

47. Zhou, H.; Zhuo, G. L.; Jiang, X. Z. J. Mol. Catal. A: Chem. 2006, 248, 26-31. doi:10.1016/j.molcata.2005.12.007

48. Li, J.; Cui, H.; Song, X.; Zhang, G.; Wang, X.; Song, Q.; Wei, N.; Tian, J. RSC Adv. 2016, 6, 92402-92410. doi:10.1039/C6RA18783H

49. Cao, Y.; Ran, R.; Wu, X.; Zhao, B.; Wan, J.; Weng, D. Appl. Catal., A 2013, 457, 52-61. doi:10.1016/j.apcata.2013.03.002

50. Hosseini-Sarvari, M.; Razmi, Z.; Doroodmand, M. M. Appl. Catal., A 2014, 475, 477-486. doi:10.1016/j.apcata.2014.02.002

51. Zhu, X.; Zhang, Q.; Su, W. RSC Adv. 2014, 4, 22775-22778. doi:10.1039/c4ra02952f

52. Schmidt, R.; Burmeister, C. F.; Baláž, M.; Kwade, A.; Stolle, A. Org. Process Res. Dev. 2015, 19, 427-436. doi:10.1021/op5003787

53. Yu, J.-B.; Peng, G.; Jiang, Z.-J.; Hong, Z.-K.; Su, W.-K. Eur. J. Org. Chem. 2016, 5340-5344. doi:10.1002/ejoc.201600987

54. Stolle, A.; Schmidt, R.; Jacob, K. Faraday Discuss. 2014, 170 , 267-286. doi:10.1039/C3FD00144J

55. Hernández, J. G.; Turberg, M.; Schiffers, I.; Bolm, C. Chem. - Eur. J. 2016, 22, 14513-14517. doi:10.1002/chem.201603057

56.Zou, Y.; Chen, C.; Chen, X.; Zhang, X.; Rao, W. Eur. J. Org. Chem. 2017, 2266-2271. doi:10.1002/ejoc.201700088

57. Jiang, Z.-j.; Wang, W.; Zhou, R.; Zhang, L.; Fu, H.-y.; Zheng, X.-I.; Chen, H.; Li, R.-x. Catal. Commun. 2014, 57, 14-18. doi:10.1016/j.catcom.2014.07.031

\section{License and Terms}

This is an Open Access article under the terms of the Creative Commons Attribution License (http://creativecommons.org/licenses/by/4.0), which permits unrestricted use, distribution, and reproduction in any medium, provided the original work is properly cited.

The license is subject to the Beilstein Journal of Organic Chemistry terms and conditions:

(http://www.beilstein-journals.org/bjoc)

The definitive version of this article is the electronic one which can be found at: $\underline{\text { doi: } 10.3762 / \text { bjoc. } 13.160}$ 